\title{
Measurement of concentrations of Faecal Glucocorticoid Metabolites in free-RAnging African Elephants Within the Kruger National Park
}

\author{
JOZUA J. VILJOEN \\ ${ }^{1}$ Department of Nature Conservation \\ Tshwane University of Technology \\ South Africa \\ ${ }^{2}$ Mammal Research Institute \\ Department of Zoology and Entomology \\ University of Pretoria \\ South Africa \\ ANDRE GANSWINDT \\ Section of Veterinary Wildlife Studies \\ Faculty of Veterinary Science \\ University of Pretoria \\ South Africa \\ German Primate Centre \\ Department of Reproductive Biology \\ Germany \\ RUPERT PALME \\ Institute of Biochemistry \\ Department of Natural Sciences \\ University of Veterinary Medicine \\ Austria \\ HENDRIK C. REYNECKE ${ }^{1}$ \\ JOHAN T. DU TOIT ${ }^{2}$ \\ Department of Wildland Resources \\ Utah State University \\ USA \\ WILLIAM R. LANGBAUER JR \\ Pittsburgh Zoo \& PPG Aquarium \\ USA \\ Correspondence to: Jozua J. Viljoen \\ e-mail: viljoenjj@tut.ac.za
}

Postal Address: Tshwane University of Technology, Private Bag X680, Pretoria, 0001, South Africa

\section{ABSTRACT}

During the past several years, non-invasive monitoring of steroid metabolites in faeces of elephants has become an increasingly popular technique to generate more information about the causal relationship between hormones and behaviour in both living elephant species. This is important knowledge which can be used to optimise local conservation and wildlife management by finding new strategies for better elephant population management and control. In this context, however, information about an actual involvement of the hypothalamic-pituitary-adrenal axis during assumable stressful events is still limited, especially for wildlife populations. One difficulty in discovering such information is often the lack of reliable data for hormone baseline levels. Therefore, the aim of this study was to determine baseline concentrations of faecal glucocorticoid metabolites that could be expected within age classes and between seasons in African elephants (Loxodonta africana) in the Kruger National Park (KNP). A total of 374 faecal samples were collected from randomly located family herds in the southern KNP between May 2002 and August 2005. The samples were analysed for immunoreactive concentrations of faecal glucocorticoid metabolites using a validated enzyme immunoassay for $3 \alpha, 11$ oxo-cortisol metabolites $(3 \alpha, 11$ oxo-CM). All samples were grouped according to the estimated age class of the subject using a field method based on bolus diameter, and regarding the ecological season collected. No significant differences in faecal $3 \alpha, 11$ oxo-CM concentrations were found across age classes $\left(\mathrm{H}_{3}=7.54 ; \mathrm{p}=0.057\right)$, but the mean $3 \alpha, 11$ oxo-CM concentration of samples collected in the dry season $(n=196)$ was significantly higher than in the wet season $(n=178)(u=15206.50 ; p=0.032)$, which indicates a possible physiological stress situation due to a decline in food quantity and quality. The information generated in this study represents a reliable data set for baseline concentrations of faecal glucocorticoid metabolites for elephants within the KNP and can be used to measure the stressrelated effects of translocations, management actions and the impact of chosen land use activities.

Keywords: glucocorticoid metabolites, faecal, baseline, African elephant, enzyme immunoassay 
A free-ranging animal is in a state of stress if it is required to make abnormal or extreme adjustments in its physiology or behaviour in order to cope with adverse aspects of its environment or management (Friend 1980). From the physiological perspective, several endocrine responses are, amongst others, involved during stress situations. The frontline hormones to overcome these situations are the glucocorticoids, which are indicators of adrenal activity and thus of stress (Möstl \& Palme 2002). As a physiological mechanism, stress is not inherently negative (Moberg 2000), however, prolonged high concentrations of glucocorticoids may decrease individual fitness (Munck et al. 1984) and reproductive success (Liptrap 1993), which may cascade into long-term behavioural changes.

The assessment of adrenal endocrine function in vertebrates via blood samples was an often used tool in the past, but the procedure in itself can elicit a glucocorticoid response (Möstl \& Palme 2002). In order to avoid such self-induced stress responses, the use of non-invasive methodologies for endocrine assessment is necessary. The collection of urine or faeces as basic material for endocrine analysis seems to be a reliable alternative to blood hormone measurements, which is demonstrated by the large number of established non-invasive methodologies for monitoring adrenal function in a variety of different mammalian species (Goymann et al. 1999; Wasser et al. 2000, Sands \& Creel 2004), including elephants (Brown et al. 1995, Ganswindt et al. 2003).

Brown et al. (1995) successfully developed and validated a method to assess adrenal function non-invasively through the analysis of cortisol in urine from captive elephants, but due to the practical difficulties involved with collecting urine samples in areas with absorptive ground, this method would not be an option for regular sampling from elephants in the wild. Faecal samples offer the advantage that they can easily be collected, and a few non-invasive methods have already been developed and successfully tested to enable the measurement of glucocorticoid metabolites in elephant faeces (Stead et al. 2000, Wasser et al. 2000, Foley et al. 2001, Ganswindt et al. 2003; 2005). In this respect, it could be shown that a pharmacologically induced physiological stress response, induced via administration of adrenocorticotropic hormone (ACTH), could be monitored in captive African elephants. Although work on free-ranging African elephants has been limited, Ganswindt et al. (2005) found that elevated androgen levels in free-ranging male African elephants could not be related to the age of the individual. Seasonal effects however do appear to influence concentrations of faecal glucocorticoid metabolites, as Foley et al. (2001) found the highest concentrations during the dry season. However, a regular sample collection at a certain time before and after a predictable stressful event is necessary to create a reliable baseline for comparison, which already underlines the importance of known baseline levels to reliably determine if any specific situation is more or less stressful than the norm.

We suggest, for example, a stressful situation can be triggered in elephants by several stimuli, including environmental factors (food quality and quantity): behavioural (courtship and mating); and psychosocial causes (translocation, culling). More information on the endocrine regulation of potential stressrelated events is needed, as the effect of human and natural disturbances on elephant populations has been restricted to behavioural indicators (Whyte 2003). It is still not known what constitutes a naturally occurring stressful situation for freeranging elephants, or which management actions or land use practices will result in elevated stress indicators.

In this paper we provide a quantitative baseline measure of concentrations of faecal glucocorticoid metabolites, after taking age and seasonal effects into account, in order to start establishing baseline levels for elephants in the Kruger National Park (KNP).

\section{MATERIALS AND METHODS}

\section{Study area and population}

The study area is located in the KNP and falls within the Lebombo Arid Mountain Bushveld, Sweet Lowveld Bushveld and Mixed Lowveld Bushveld vegetation types (Low \& Rebelo 1996). The KNP covers an area of approximately $19000 \mathrm{~km}^{2}$ and can be longitudinally divided into resistant granites in the west, succeeded by ecca shales, basalt and rhyolites in the east, that give rise to different soil types and the associated flora and fauna (Venter et al. 2003). Data collection was restricted to the southern KNP and extended from the Sabie and Crocodile River thickets, Sclerocarya birrea subsp. caffra/Acacia nigrescens Savanna, mixed Combretum to the Lebombo south landscapes.

\section{Sampling}

A matriarch of a family herd (median size 12) was fitted with a VHF radio collar and this group was followed on foot so as not to bias sampling close to roads. Samples were collected as soon as possible after an individual had defecated, from individuals in the collared group as well as from family herds (median size 13) located within the study area. We tried to exclude individual bias by collecting samples throughout each feeding patch used by a family herd. When there were obvious signs that a herd had detected our presence, such as a definite orientation towards or away from us, no samples were collected, in order to avoid the collection of stress-induced samples. All samples were collected between 07:00 and 11:00 am. Rubber gloves were used to collect approximately 100 grams of faecal material that was then placed in a labelled plastic bag. The time lapsed between defecation and the freezing of a sample was standardised to a maximum of two hours. Each sample was marked with the date of collection, a GPS coordinate, and the estimated age class of the subject using a field method based on the bolus diameter as described by Wimberger (2001).

Faecal samples were collected over the four ecological seasons as classified by Zambatis (2002), namely early dry (May-July); late dry (Aug-Oct), early wet (Nov-Jan) and late wet (Feb-April). This allowed us to determine, through concentrations of glucocorticoid metabolites, whether environmental factors, which change between seasons, have any possible influence on physiological stress. Samples $(n=374)$ were collected between May 2002 and August 2005. The average annual rainfall during the study was $572 \mathrm{~mm}$, which is in the known average annual rainfall range of $500-700 \mathrm{~mm}$ for this region, and therefore would not have unduly influenced environmentally induced feeding stress (Venter et al. 2003)

\section{Faecal extraction and hormone assays}

Faecal samples were extracted according to the procedure described by Merl et al. (2000). In brief, $0.5 \mathrm{~g}$ faeces plus $1 \mathrm{ml}$ water and $4 \mathrm{ml}$ methanol were vortexed for 30 minutes and centrifuged at $2000 \mathrm{~g}$ for 15 minutes. A quantity of $1 \mathrm{ml}$ of the supernatant was mixed with $5 \mathrm{ml}$ ethyl ether and $0.25 \mu \mathrm{l}$ of a $5 \% \mathrm{NaHCO}_{3}$ solution, and centrifuged at $2000 \mathrm{~g}$ for $15 \mathrm{~min}$. The aqueous phase was frozen at $-20{ }^{\circ} \mathrm{C}$ overnight and then the ether was decanted and dried down under a stream of $\mathrm{N}_{2}$. Following evaporation, the samples were reconstituted in an assay buffer and taken to assay.

Faecal extracts were measured for immunoreactive glucocorticoid metabolites using an enzyme immunoassay

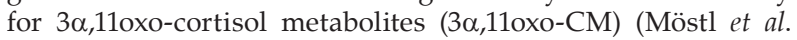
2002), which has previously been shown to provide reliable information on adrenocortical function in the African elephant (Ganswindt et al. 2003; 2005). Briefly, $50 \mu$ l aliquots of standards, quality controls, and diluted faecal extracts were pipetted in duplicate into microtiterplate wells. A total of $100 \mu \mathrm{l}$ of biotinylated label and antiserum (raised in a rabbit against $5 \beta$ Androstane-3 $\alpha$-ol-11-one-17-CMO) were added and the plates incubated overnight at $4{ }^{\circ} \mathrm{C}$. Following incubation, the plates 
were washed four times and $250 \mu \mathrm{l}(4.2 \mathrm{mU})$ of streptavidin horseradish peroxidase conjugate added to each well. Following incubation in the dark for $45 \mathrm{~min}$ at $4{ }^{\circ} \mathrm{C}$, plates were washed again, before $250 \mu \mathrm{l}(69.4 \mathrm{nmol})$ tetramethylbenzidine was added and plates further incubated $\left(45 \mathrm{~min} ; 4^{\circ} \mathrm{C}\right)$. The reaction was terminated by adding $50 \mu \mathrm{l}$ of $2 \mathrm{M} \mathrm{H}_{2} \mathrm{SO}_{4}$ and the absorbance measured at $450 \mathrm{~nm}$ (reference filter: $620 \mathrm{~nm}$ ) with an automated plate reader. Sensitivities of the assays at $90 \%$ binding were $3.0 \mathrm{pg} /$ well and intra- and interassay coefficients of variation, determined by repeated measurements of high and low value quality controls ranged between $3.0 \%$ and $12.5 \%$, respectively.

\section{Statistical analysis}

The age class data, as well as the data from the ecological season, was tested for normality using the Shapiro-Wilks W test. The data sets were not normally distributed and subsequently subjected to non-parametric statistical methods. An ANOVA was performed to test for the possible effect of age and season on concentrations of faecal glucocorticoid metabolite levels. The computer program STATISTICA (STASOFT. 1995) was used for all statistical analyses. All tests were two-tailed, with the $\alpha$ level of significance set at 0.05 . In cases of all pair-wise multiple comparison procedures, the $\alpha$-level was adjusted by applying the procedure described by Holm (1979).

\section{RESULTS}

Nosignificant variation in concentration sof faecal glucocorticoid metabolites $\left(H_{3}=7.54 ; N=374 ; P=0.057\right)$ was found across age classes (Table 1). Therefore, the age classes were combined for further analysis. Although no significant differences in concentrations of faecal glucocorticoid metabolites were found between the four ecological seasons (Table 2), there was a statistically significant difference $(u=15206.50 ; p=0.032)$ between the wet season $(n=178)$ and dry season $(n=196)$, after the early and late period of both the dry and wet seasons were combined (Figure 1).

\section{DISCUSSION}

This study provides new information on baseline concentrations of faecal glucocorticoid metabolites that could be expected within age classes and between seasons in African elephants in

TABLE 1

$\mathrm{N}$, mean, standard deviation (concentrations of faecal glucocorticoid metabolites (ng/g WW)) in the four ecological seasons (age classes separate) for free-ranging $(\mathrm{ng} / \mathrm{g} \mathrm{WW})$ ) in the four ecological seasons (age classes separate) for free-rangir
family herds of elephants in KNP from May 2002 to August 2005 .

\begin{tabular}{|c|c|c|c|c|c|c|}
\hline \multirow[t]{2}{*}{ SEASON } & \multicolumn{2}{|c|}{ ADULTS } & \multicolumn{2}{|c|}{ SUB-ADULTS } & \multicolumn{2}{|c|}{ JUVENILES } \\
\hline & $\mathbf{N}$ & $\begin{array}{l}3 \alpha, 110 \times 0-C M \\
\text { Conc. } \\
\text { (mean } \pm S T D \text { ) }\end{array}$ & $\mathbf{N}$ & $\begin{array}{l}3 \alpha, 110 \times 0-C M \\
\text { Conc. } \\
\text { (mean } \pm S T D \text { ) }\end{array}$ & $\mathrm{N}$ & 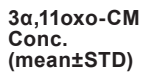 \\
\hline Early Dry & 68 & $85.19,47.08$ & 50 & $94.04,44.23$ & 28 & $91.29,56.22$ \\
\hline Late Dry & 23 & $79.70,70.68$ & 17 & $88.71,69.90$ & 10 & $80.10,46.53$ \\
\hline Early Wet & 39 & $72.62,43.39$ & 23 & $68.48,38.71$ & 14 & $101.79,54.27$ \\
\hline Late Wet & 41 & $67.61,39.48$ & 36 & $82.25,48.51$ & 25 & $81.36,59.68$ \\
\hline
\end{tabular}

TABLE 2

$\mathrm{N}$, mean, standard deviation (concentrations of faecal glucocorticoid metabolites (ng/g WW)) in the four ecological seasons (age classes combined) for free-ranging family herds of elephants in KNP from May 2002 to August 2005.

\begin{tabular}{|c|c|c|}
\hline \multirow[t]{2}{*}{ SEASON } & \multicolumn{2}{|c|}{ INDIVIDUALS } \\
\hline & $\mathbf{N}$ & 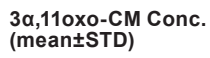 \\
\hline Early Dry & 146 & $89.39,47.86$ \\
\hline Late Dry & 50 & $82.84,65.23$ \\
\hline Early Wet & 76 & $76.74,45.29$ \\
\hline Late Wet & 102 & $76.15,48.26$ \\
\hline
\end{tabular}

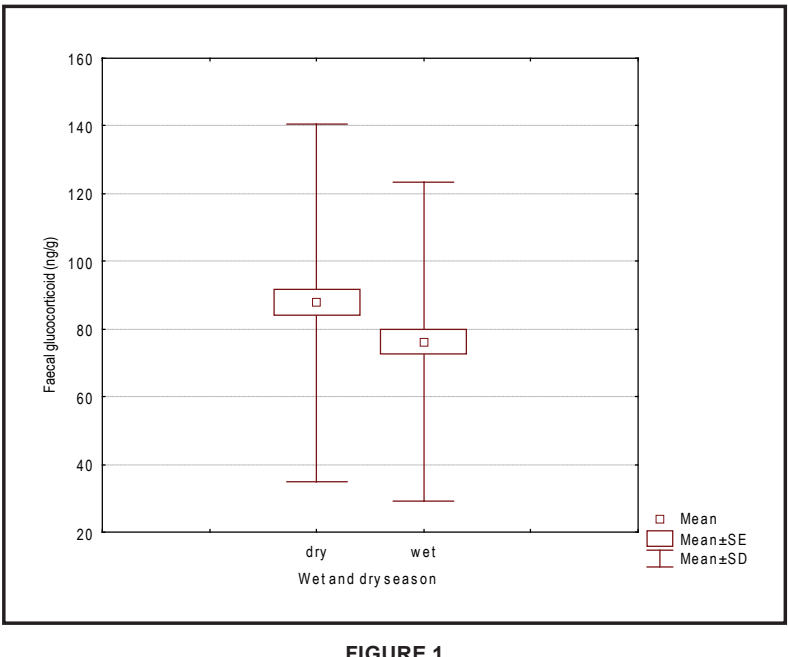

Box-plots of grouped concentrations of immunoreactive faecal glucocorticoid metabolites (ng/g) for free-ranging family herds of elephants in KNP in the dry and wet seasons from May 2002 to August 2005.

the southern Kruger National Park. Our results show that the variability in baseline concentrations of faecal glucocorticoid metabolites ( $3 \alpha, 110 x 0-\mathrm{CM}$ levels) in African elephant faeces is dependent on seasonal changes, rather than on the age class of the subject. In the present study faecal $3 \alpha, 11$ oxo-CM levels differ significantly between seasons, but no differences were found across age classes. Although the seasonal effect found seems to be rather small, future studies using methods of faecal hormone analysis to determine the effect of a potential stressor should account for seasonal effects, especially between the wet and dry season.

The fact that no significant variation in faecal $3 \alpha, 110 x 0-\mathrm{CM}$ levels was found across age classes confirm findings by Ganswindt et al. (2005), who also reported no age effects on $3 \alpha, 11$ oxo-CM levels in a group of African elephant bulls ( $\mathrm{n}=$ 52, age range: $18-49$ years) living in the Samburu and Buffalo Springs National Reserves, Kenya. In the same study, Ganswindt and colleagues described a small but clear elevation in $3 \alpha, 11$ oxo-CM levels in longitudinal hormone profiles of African elephant bulls at the end of a long dry period (Ganswindt et al. 2005). A correlation between season-dependent rainfall and adrenal endocrine function (highest concentrations of faecal glucocorticoid metabolites in the dry season) was further described for female elephants by Foley et al. (2001). The present study confirms a possible influence of a dry period on increased glucocorticoid excretion, because the mean concentration of faecal glucocorticoid metabolites of samples collected in the dry season was significantly higher than in the wet season. The elevation of concentrations of faecal glucocorticoid metabolites during the dry season could be an indication of increased physiological stress due to a decline in food quantity and quality. This was a suggestion already made by Codron et al. (2006), who reported that the percentage of nitrogen in elephant faeces from the southern KNP showed a dramatic increase from the dry to the wet season. An elevation of nitrogen in faeces is known as a useful indicator of nutritional status.

We could unfortunately not investigate differences in concentrations of faecal glucocorticoid metabolites between sexes due to safety considerations for the observers (distance away from the herd), and visual impairment caused by vegetation structure. However, further studies should examine the difference in $3 \alpha, 11$ oxo-CM levels between the sexes after intense sampling from cows and bulls within both seasons, because sex could be a co-factor for the variability in baseline concentrations of faecal glucocorticoid metabolites. Greyling (2004) found that during periods of resource limitation, males showed significantly lower levels of faecal minerals, together 
with higher levels of fibre, than adult females. These results indicate that males could be maintaining diets of poorer quality than females and consequently be nutritionally more stressed than females during the dry season.

Further studies should also investigate the difference in concentrations of faecal glucocorticoid metabolites between elephants from different areas, which would finally allow a comparison of mean concentrations of faecal glucocorticoid metabolites across elephant management regions within the KNP (Whyte et al. 2003). This would aid in creating a baseline for the entire park; that would be per season, per region and between different elephant densities. Finally, this information could also be applied more universally, e.g. if a significant correlation with average monthly rainfall can be shown, or whether a direct correlation exists between increasing physiological stress and vegetation damage.

\section{CONCLUSION}

A validated method (EIA) was applied in assessing the level of physiological stress in free-ranging elephant herds. The method has been shown to be practical and enables long-term monitoring of ethological or environmental factors without interfering with the result.

\section{ACKNOWLEDGEMENTS}

South African National Parks is thanked for allowing fieldwork in the Kruger National Park. Dr I. Whyte and Prof. D. G. A. Meltzer for their assistance. We are grateful to Mrs A. Human for the laboratory work. We thank the field rangers of the Lower Sabie section for providing protection during data collection. The South African National Research Foundation and Pittsburgh Zoological Society provided funding.

\section{REFERENCES}

Brown, J.L., C.M. Wemmer \& J. Lehnhardt. 1995. Urinary cortisol analysis for monitoring adrenal activity in elephants. Zoo Biology 14: 533-542.

Codron, J. J., Lee-Thorp, A., Sponheimer, M., Codron, D., Grant, R.C \& De Ruiter, D.J. 2006. Elephant (Loxodonta africana) diets in Kruger National Park, South Africa: Spatial and Landscape differences. Journal of Mammalogy 87(1): 27-34

Friend, T.H. 1980. Stress: What is it and how can it be quantified? Int J Stud Anim Prob 1 (6): 366-373.

Foley, C.A.H., Papageorge,S.\& Wasser, S.K. 2001. Non-invasive stress and reproductive measures of social and ecological pressures in free-ranging African elephants (Loxodonta africana). Conservation Biology 15: 1134-1142.

Ganswindt A., Heistermann, M., Palme, R., Borragan, S. \& Hodges, J.K. 2003. Non-invasive assessment of adrenal function in the male African elephant (Loxodonta africana) and its relation to musth. Gen Comp Endocrinal 134: 156-166.

Ganswindt, A., Rasmussen, H.B., Heistermann, M. \& Hodges, J.K. 2005. The sexually active states of free-ranging male African elephants (Loxodonta africana): Defining musth and non-musth using endocrinology, physical signals, and behaviour. Horm Behav 47 (1): 83-91.
Goymann, W., Möstl, E., Van't Hof, T, East, M.L. \& Hofer, H. 1999. Noninvasive Fecal Monitoring of Glucocorticoids in Spotted Hyenas, Crocuta crocuta. Gen. Comp. Endocrinal 114: 340-348.

Greyling, M.D. 2004. Sex and age related feeding distinctions in the feeding ecology of the African elephant, Loxodonta africana. Ph.D Thesis, University of the Witwatersrand, Johannesburg.

Holm, S. 1979. A simple sequentially rejective multiple test procedure. Scandinavian Journal of Statistics 6:65-70.

Liptrap, R.M. 1993. Stress and reproduction in domestic animals. Ann NY Acad Sci 697: 275-84.

Low, A. B. \& Rebelo, A. G. 1996. Vegetation of South Africa, Lesotho and Swaziland. Department of Environmental Affairs \& Tourism, Pretoria.

Merl, S., Scherzer, S., Palme, R. \& Möstl, E. 2000. Pain causes increased concentrations of glucocorticoid metabolites in horse faeces. J Equine Vet Sci 20: 586-90.

Moberg, G.P. 2000. Biological response to stress: implications for animal welfare. In: Moberg, G.P. \& Mench, J.A. (Eds.) The biology of animal stress. Pp. 123-46, CABI Publishing, 2000.

Möstl, E., Maggs, J.L., Schrötter, G., Besenfelder, U.\& Palme, R. 2002. Measurement of cortisol metabolites in faeces of ruminants. Vet Res Commun 26: 127-39.

Möstl, E. \& Palme, R. 2002. Hormones as indicators of stress. Domestic Animal Endocrinology 23: 67-74.

Munck, A., Guyre, P.M. \& Holbrook, N.I. 1984. Physiological function of glucocorticoids in stress and their relationship to pharmacological actions. Endocr. Rev. 5: 25-44.

Sands, J. \& Creel, S. 2004. Social dominance, aggression and faecal glucocorticoid levels in a wild population of wolves, Canis lupus. Anim. Behav. 67, 387-396.

StaSoft. 1995. Statistica for Windows. StaSoft, Inc., 2300 East 14th Street, Tulsa, OK U.S.A.

Stead, S.K., Meltzer, D.G.A. \& Palme, R. 2000. The measurement of concentrations of faecal glucocorticoid metabolites in the serum and faeces of captive African elephants (Loxodonta africana) after ACTH stimulation. Tydskr. S.Afr. Vet 71(3): 192-195.

Venter, F. J, R., Scholes, J.\& Eckhardt, H. C. 2003. The abiotic template and its associated vegetation pattern. In: Du Toit, J. T., Rogers, K. H. \& Biggs, H. C. (Eds.) Pp.83-129, Island Press, Washington, D.C.

Wasser, S. K., Hunt, K.E., Brown, J.L., Cooper, K., Crockett, C.M., Bechert, U., Millspaugh, J.J., Larson, S.\& Monford, S.L. 2000. A generalized faecal glucocorticoid Assay for use in a diverse array of non-domestic mammalian and avian species. Gen Comp Endocrinol 120: 260-75.

Whyte, I. 2003. The movement patterns of elephant in the Kruger National Park in response to culling and environmental stimuli. Pachyderm 16:72-80.

Whyte, I. J., Van Aarde, R.J., Pimm, S.L. 2003. Kruger's elephant population: Its size and consequences for ecosystem heterogeneity. In: J. T. Du Toit, Rogers, K. H. \& Biggs, H. C., (Eds.) Pp.332-348, Island Press, Washington, D.C.

Wimberger, K. 2001. Aging free-ranging African elephants (Loxodonta africana) using faecal bolus diameter. Recitation for BSc Honours. Department of Zoology and Entomology, University of Pretoria. (Unpublished)

Zambatis, N. 2002. Annual section ranger reports. KNP vegetation monitoring. Scientific services KNP. (Unpublished) 